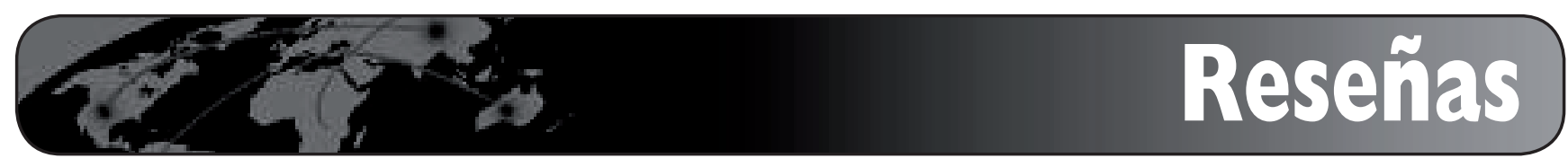

\title{
Prensa digital y bibliotecas (Ernest Abadal y Javier Guallar)
}

\author{
Por Ramón Salaverría
}

Salaverría, Ramón. "Prensa digital y bibliotecas (Ernest Abadal y Javier Guallar)”. Reseña de libro. El profesional de la información, 2010, julio-agosto, v. 19, n. 4, pp. 439-440.

DOI: $10.3145 /$ epi.2010.jul.16

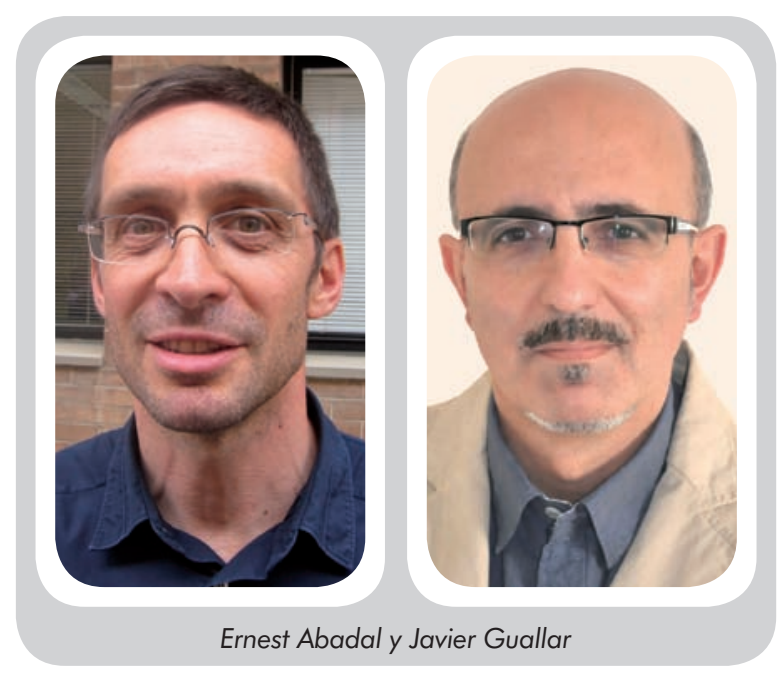

En esta categoría transversal podrían encuadrarse obras pioneras como el directorio Medios de comunicación en internet: guía de navegación (Javier Díaz-Noci; Koldo Meso-Ayerdi, 1997), manuales como la Guía de internet para periodistas (Víctor M. Pareja (coord.), 2003) publicada por el Cindoc, o monografías

EN LA ÚLTIMA DÉCADA buena parte de la literatura académica sobre la documentación y sobre el periodismo ha discurrido por terrenos próximos: en ambas disciplinas muchas de las publicaciones se han centrado en examinar el impacto de las tecnologías digitales en la información.

Ese interés común tenía pleno fundamento, puesto que la digitalización se ha revelado el principal factor reconfigurador de los procesos, las herramientas y las formas de tratar la información, ya sea documental o periodística.

Muchas publicaciones han analizado por separado estos fenómenos en el campo de la documentación o el periodismo. Sin embargo no son tantas las que se han aventurado a describir y analizar en el contexto digital los territorios fronterizos entre ambas disciplinas. como Documentación informativa en el periodismo digital (María Rubio-Lacoba, 2007).

El presente libro, Prensa digital y bibliotecas, de los profesores de la Universitat de Barcelona Ernest Abadal y Javier Guallar, constituye una aportación de gran valor en este terreno a caballo entre las ciencias de la documentación y el

Aunque el libro interesará sin duda a los investigadores especializados en estas disciplinas, se trata como apoyo didáctico en el aula. $\mathrm{Su}$ extensión moderada (170 páginas) y su proverbial claridad expositiva, alejada de cualquier atisbo de erudición superflua pero no exenta de poso académico, propician que cualquier alumno pueda asimilar con facilidad los conceptos abordados en esta monografía. periodismo. de un manual apto para ser utilizado



Abadal, Ernest; Guallar, Javier. Prensa digital y bibliotecas. Gijón: Ediciones Trea, 2010, 170 pp. ISBN: 978-84-9704-446-2.

Estos conceptos, tal y como anuncia el título, discurren por dos caminos fundamentales: la identificación de las características de la prensa digital y la descripción de los recursos documentales relacionados con la información periodística en la Red.

Al primero de estos dos asuntos dedican los autores el capítulo inicial, "Prensa digital", el más extenso (pp. 23-94). En esta parte se destilan ordenadamente muchos de los conceptos teóricos y conocimientos 
empíricos que se han ido sedimentando en los últimos años en torno al ciberperiodismo. Aquí se abordan asuntos tratados por autores precedentes, como por ejemplo el debate sobre la designación de esta variante del periodismo y de sus conceptos relacionados. También se desgranan temas como las tecnologías digitales empleadas para la difusión de contenidos periodísticos en las últimas tres décadas, las etapas históricas de la prensa digital, los rasgos distintivos de la comunicación digital y la taxonomía formal de los medios digitales. El capítulo termina con una ponderada prospectiva de futuro, sin olvidar otros aspectos colaterales relevantes, como la evolución de las audiencias y los modelos de negocio.

La contribución más sustantiva del libro llega con los capítulos 2 y 3: "Fuentes de información sobre prensa digital" (pp. 95-126) y "La prensa digital en la biblioteca" (pp. 127-148).

En estas páginas se describen en primer lugar las principales fuentes de información para el acceso y consulta de los diarios digitales y de sus contenidos. Estas fuentes se organizan en cuatro tipos de recursos:
1) orientados al acceso a cabeceras de prensa, ción,

2) los de búsqueda de informa-

3) para el seguimiento de la información y, por último,

4) los orientados a la agregación de contenidos.

Se trata de una cartografía documental completa, donde encuentran acomodo no sólo los recursos bien conocidos por la mayoría de los lectores de prensa digital, sino también otros más avanzados y especializados, de modo que tanto periodistas como documentalistas hallarán aquí un buen conjunto de referencias de provecho.

Más netamente orientado a los profesionales de la documentación es el capítulo final, donde se analizan las fórmulas, desafíos y posibilidades de aprovechamiento de las publicaciones digitales por parte de las bibliotecas.

El libro cuenta con un prólogo escrito por Javier Díaz-Noci y un epílogo de Lluís Codina, dos de los investigadores de referencia en el ámbito del ciberperiodismo y la documentación digital, respectiva- mente. El detalle no es casual, desde luego. Es otra forma de recordarnos que, entre lo netamente periodístico y lo marcadamente documental, se abre un territorio nuevo y mutuamente enriquecedor, donde Abadal y Guallar demuestran moverse de manera sobresaliente.

\section{Referencias}

Díaz-Noci, Javier; Meso-Ayerdi, Koldo. Medios de comunicación en internet: guía de navegación. Madrid: Anaya, 1997, 192 p.

Pareja, Víctor-Manuel (coord.). Guía de internet para periodistas. Madrid: Centro de Información y Documentación Cindoc (CSIC), 2003, $196 \mathrm{p}$.

Rubio-Lacoba, María. Documentación informativa en el periodismo digital. Madrid: Síntesis, 2007, $143 \mathrm{p}$.

Ramón Salaverría, doctor en periodismo, es profesor titular en la Facultad de Comunicación de la Universidad de Navarra, donde dirige el Departamento de Proyectos Periodísticos. Especializado en ciberperiodismo, es autor, entre otros libros, de Periodismo integrado (2008) y Redacción periodística en internet (2005).

http://www.unav.es/fcom/profesores/ salaverria.htm

rsalaver@unav.es

\title{
Próximos temas centrales
}

\author{
Septiembre 2010 \\ Cooperación de bibliotecas en red \\ Noviembre 2010 \\ Medios de comunicación en internet \\ Enero 2011 \\ Psicología y sociología de la información \\ Marzo 2011 \\ Archivos administrativos e intranets \\ Mayo 2011 \\ Información de las administraciones públicas \\ Julio 2011 \\ Documentación fotográfica \\ Septiembre 2011 \\ Inteligencia competitiva \\ Los interesados pueden remitir notas, artículos, propuestas, publicidad, comentarios, etc., \\ sobre estos temas a: http://recyt.fecyt.es/index.php/EPI/index
}

